\title{
Co-constructing desired activities : Small-scale activity decisions in occupational therapy
}

\section{Weiste, Elina}

Palgrave Macmillan

2020

Weiste , E 2020 , Co-constructing desired activities : Small-scale activity decisions in occupational therapy . in C Lindholm , M Stevanovic \& E Weiste (eds), Joint Decision Making in Mental Health : An Interactional Approach. The Language of Mental Health, Palgrave Macmillan , Cham , pp. 235-252 . https://doi.org/10.1007/978-3-030-43531-8_10

http://hdl.handle.net/10138/331661

https://doi.org/10.1007/978-3-030-43531-8_10

unspecified

acceptedVersion

Downloaded from Helda, University of Helsinki institutional repository.

This is an electronic reprint of the original article.

This reprint may differ from the original in pagination and typographic detail.

Please cite the original version. 
To cite: Weiste, Elina (2020). Co-constructing desired activities: Small-scale activity decision in occupational therapy. In Camilla Lindholm, Melisa Stevanovic \& Elina Weiste (eds.), Joint decision making in mental health: An interactional approach (pp. 235-252). Basingstoke, UK: 


\title{
Chapter 10: Co-constructing desired activities: Small-scale activity decisions in occupational therapy
}

\author{
Elina Weiste
}

\begin{abstract}
In occupational therapy, a therapist and client engage in shared activities that they perform collaboratively during therapeutic sessions. An important part of this joint performance involves providing the client with the opportunity to make short-term decisions on the activities they wish to perform. Analyzing 15 occupational therapy encounters at psychiatric outpatient clinics, in the chapter I explore the functions of these small-scale decisions. The analysis demonstrates that therapists (1) make room for the client's proposals by shaping the activity context and (2) make proposals themselves on the ways the performance should be accomplished. To summarize, clients are given decision-making power over the content of the activity, whereas therapists use their decision-making power to assist the client's performance. The analysis shows how small-scale decisions can be employed to construct the occupational performance as shared endeavors and to position the clients as active subjects rather than objects of the professionals' performance.
\end{abstract}

Keywords: activity, collaboration, decision-making, occupational therapy, participation, proposal, psychiatric outpatient care, rehabilitation

\section{Enabling Client Participation Through Therapeutic Collaboration}

Current international mental health policy recommendations emphasize the importance of client participation (WHO, 2010). Research has shown that clients' active participation can be increased by a client-centered service model that tailors support to clients' individual 
needs and promotes their skills and confidence (e.g., Hibbard \& Greene, 2013). The core idea of this model is to elicit and understand clients' perspectives, expectations, and needs in order to reach a shared understanding of the problem and its treatment, as well as to help clients share power and responsibility by involving them in decision-making (Epstein et al., 2005, p. 1517). In shared decision-making, both parties share information and take steps to construct a joint view on the preferred treatment (Charles, Gafnv, \& Whelan, 1997).

The shared decision-making paradigm largely focuses on describing high-stakes decision-making: situations concerning treatment decisions that have a significant impact on the client's life (see Chapters 3, 5, and 7 in this volume). However, operating within a clientcentered framework also necessitates considering decision-making opportunities in "smaller," more everyday areas of life (see also Chapters 2, 6, 8, 10 and 12). Even though these smallscale decisions might lack the kind of consequentiality that characterizes treatment decisions, they are nevertheless considered important for taking the client's perspective into account and supporting the client's progress (e.g., Sumsion, 2006). This is especially the case with clients with severe mental illnesses, such as schizophrenia, which are known to impair clients' decision-making capacity (e.g., Beitinger, Kissling, \& Hamann, 2014).

However, previous research has not investigated how this small-scale decision-making is realized in interaction. This chapter complements previous research on shared decisionmaking by exploring the way the therapist and client make small-scale decisions during occupational therapy sessions. It focuses on proposals made by the occupational therapists and clients while engaged in shared activities that are meaningful to the client.

\section{Meaningful Activities as Therapeutic Interventions}

Participating in different forms of activities is fundamental to human health and wellbeing. Such activities provide meaning and structure to people's lives, are important in the 
development of identity, and reflect society's values and culture (Creek, 2014; WFOT, 2012). The aim of occupational therapy is to promote, maintain, or restore clients' wellbeing and functional independence through meaningful activities (occupations) that the clients wish to perform (WFOT, 2012). The primary goal is to enable clients to participate in the activities of everyday life: taking care of themselves, managing domestic life, coping at school and work, resting, spending leisure time, and participating in society. The therapeutic process is set to foster the client's sense of belonging and connecting to others through participation in activities that are valued in the client's social context and have potential to strengthen his or her social roles (Hammell, 2014). This therapeutic goal is achieved by working with clients to enhance their ability to engage in the activities that they wish, need, or are expected to perform or by modifying those activities or the environment to better support their engagement (WFOT, 2012).

Occupational therapists often use different types of activities meaningful to the client as therapeutic tools for precipitating changes in the client's function and performance (Creek, 2014). The desired activity is the task or occupation that the therapist and client have selected for therapy (Taylor, 2008, p. 53). Clients are actively involved in the therapeutic process, and the general goal of the interventions is to increase the client's occupational performance and develop skills to support health, wellbeing, and life satisfaction (WFOT, 2012).

In an occupational therapy process, a therapist and client engage in activities that they perform collaboratively during the therapeutic sessions. An important part of this joint performance involves providing clients with the opportunity to make small-scale decisions on the activities they wish to perform (e.g., Creek, 2014; Taylor, 2008). These activity decisions are deliberate decisions that concern what the therapist and client will do together during their joint session, usually in the following minutes (Kielhofner, 2002). 
This chapter investigates how small-scale activity decisions are jointly constructed by occupational therapists and clients. The analysis focuses on the proposals that participants make while performing an activity selected by the client, such as cooking or artwork, during the therapy session. Proposals are acts of speech in which one of the participants names a forward-looking act and suggests its implementation - proposing it to others for confirmation or rejection (Stevanovic, 2012). Proposals are of interest from the perspective of therapeutic collaboration, as participants assign their partner-in-interaction equal status to decide on future activities (Stevanovic, 2012).

\section{Research Questions}

The aim in this chapter is to complement previous work on shared decision-making by exploring the proposals therapists and clients make while engaged in a joint activity. The analysis is guided by the following research questions:

(1) What proposals do occupational therapists and clients make when engaged in a joint activity?

(2) What verbal and material resources do therapists and clients use in their proposals?

(3) How are these proposals sequentially located as part of the activity performance?

\section{Data and Method}

The data consist of 15 video-recordings of occupational therapy encounters in Finland, collected from two different psychiatric outpatient clinics. In Finland, psychiatric outpatient clinics provide psychiatric consultation, treatment and rehabilitation for the adult population of the local community. A referral from a primary care doctor is needed. A broad range of acute and chronic mental disorders is treated, and the services provided to the client free of charge. 
The length of the therapy sessions varies from 45 minutes to two hours and comprise 16 hours of interaction. The data come from three therapists with three different clients. The therapists are all qualified occupational therapists and the clients all suffer from severe mental illnesses, such as schizophrenia, schizoaffective disorder and major depression. At the time of the data collection, they were engaged in ongoing therapeutic relationships that had lasted from six months to two years. Their regular meetings were held at approximately twoweek intervals. Permission to collect the data was obtained from the municipal health authority and the ethical board of the University Central Hospital. All names and other details which could enable identification of the participants have been altered in the data extracts.

From the dataset, the sessions selected were those in which the participants engaged in joint activities. From the entire set of 16 sessions, four contained such activity-oriented sessions, during which the clients cooked and practiced several types of art. The data were analyzed by means of conversation analysis (e.g. Sidnell \& Stivers, 2013). In the analytic procedure (see e.g. Heritage, 2011), the recordings were first listened to several times, and then all the instances in which the therapist or the client made a proposal while engaged in a joint activity were selected. Other proposals outside the immediate activity context, such as decisions on what activities to perform during the sessions, were excluded from this analysis. The dataset contained 31 such small-scale decision-making sequences. In what follows, the therapeutic functions of these decision-making sequences are investigated in detail, focusing on their consequences for the subsequent interaction.

\section{Constructing a Shared Activity Through Small-Scale Decisions}

The analysis reveals that the occupational therapists performed two types of interactional work. First, they made room for the clients' proposals by shaping the activity context. They invited clients' proposals by noticing resources or materials and making them publicly visible. 
They also described their own actions and possible problems relating to the objects, making it relevant for the client to propose solutions or subsequent activity steps. Second, the occupational therapists made proposals themselves. They were used to suggest the order of activity steps or the ways the performance should be achieved. Thus, these proposals worked primarily as an aid or support for the client's occupational performance. In the following, each of these two types of proposals are illustrated through data examples.

\section{Enabling Client Proposals by Shaping the Activity Context}

In the preset data, the therapists implicitly invited the clients to make proposals by shaping the activity context. The first practice that the therapists used to invite client's proposals was to notice materials in the therapy room. By making physical objects publicly visible, the therapist invited the client to propose how to use them in order to proceed with the activity at hand. Extract 1 provides a case in point.

In Extract 1, the client $(\mathrm{C})$ and therapist $(\mathrm{T})$ have been discussing the client's anxiety attacks, and they have sought ways to manage them. They have agreed to make a note card that the client can use when feeling distressed in public spaces. Just before the extract occurs, they have written the text that will be on the card, and the therapist, who is using a computer, begins to modify the size of the text.

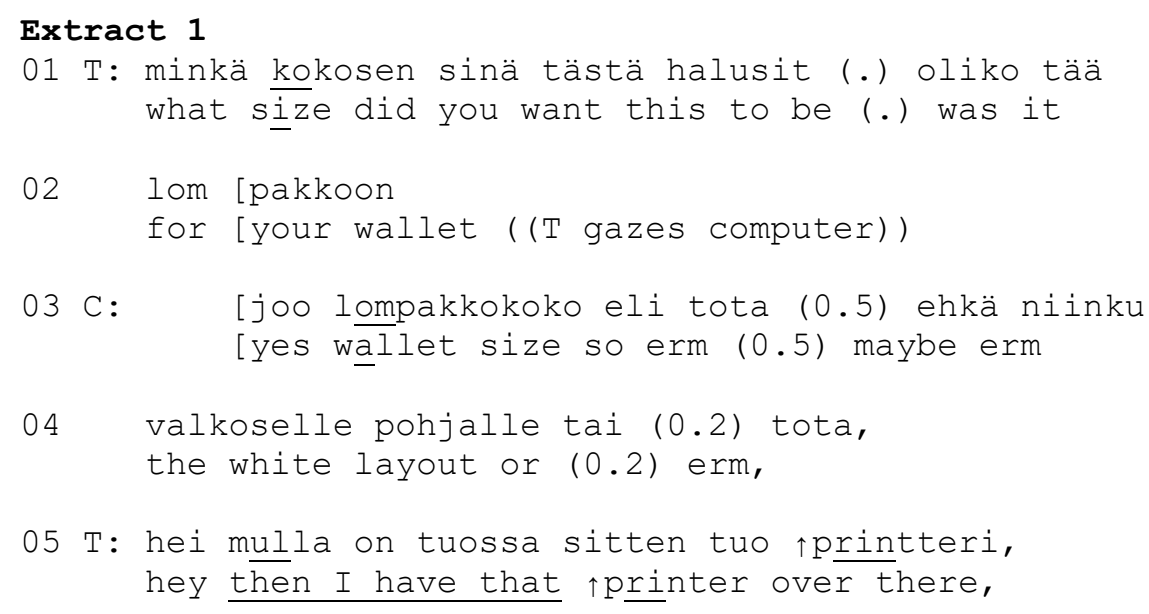




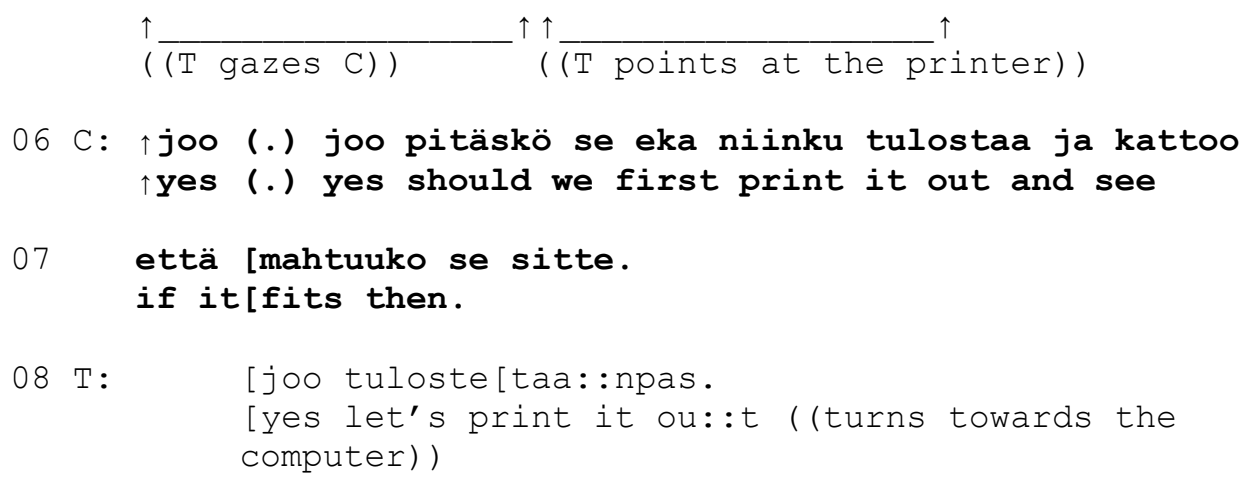

The therapist asks for the client's preferences over the size of the text to be printed on the card (line 1). The therapist also checks if the client's plan was to put the note card in her wallet. The client agrees and confirms that the card should be "wallet size" (line 3), but she has difficulty identifying the size of the text. The client hesitates, pauses her speech, and tells the therapist to use "a white background" (line 4), thereby failing to respond to the therapist's initial question about the size of the text. In line 5, the therapist makes a notable departure from the previous turns of talk: the turn is initiated with the interjection hei ("hey"), which seeks to focus the client's attention (Hakulinen, 2004, $\S 858$ ). It is followed by a statement in which the therapist notes that she has a printer on her side-desk. She also turns her gaze from the computer toward the client and points at the printer with her index finger. The printer has been there all the time, but at this point, when the object becomes interactionally relevant, she foregrounds it and makes it publicly visible (see Bergmann, 1990). In this way, the therapist provides an implicit hint to the client about how she could solve the problem of text size. In lines 6-7, the client exploits the therapist's hint and proposes that they print the text to see if the size is right. Still overlapping with the client's talk, the therapist agrees, turns towards the computer and starts to print the document (line 8).

In summary, the therapist closely monitors the client's actions, notices a physical object and makes it publicly visible, directing the client's perception towards the object. This provides the client with an implicit hint on how to proceed with the activity at hand. Rather 
than proposing a solution herself, the therapist gives the client an opportunity to solve the problem and decide how to continue with the activity.

The therapists also shape the preconditions for clients making proposals by describing their own actions related to physical objects and the possible problems therein. In this way, they make it relevant for the client to propose solutions and the next activity steps. Extract 2 provides one such example.

Prior to the extract, the therapist and client have been making refrigerator magnets with supportive messages. At the beginning of the extract, they are starting to glue the text tags onto the magnets.

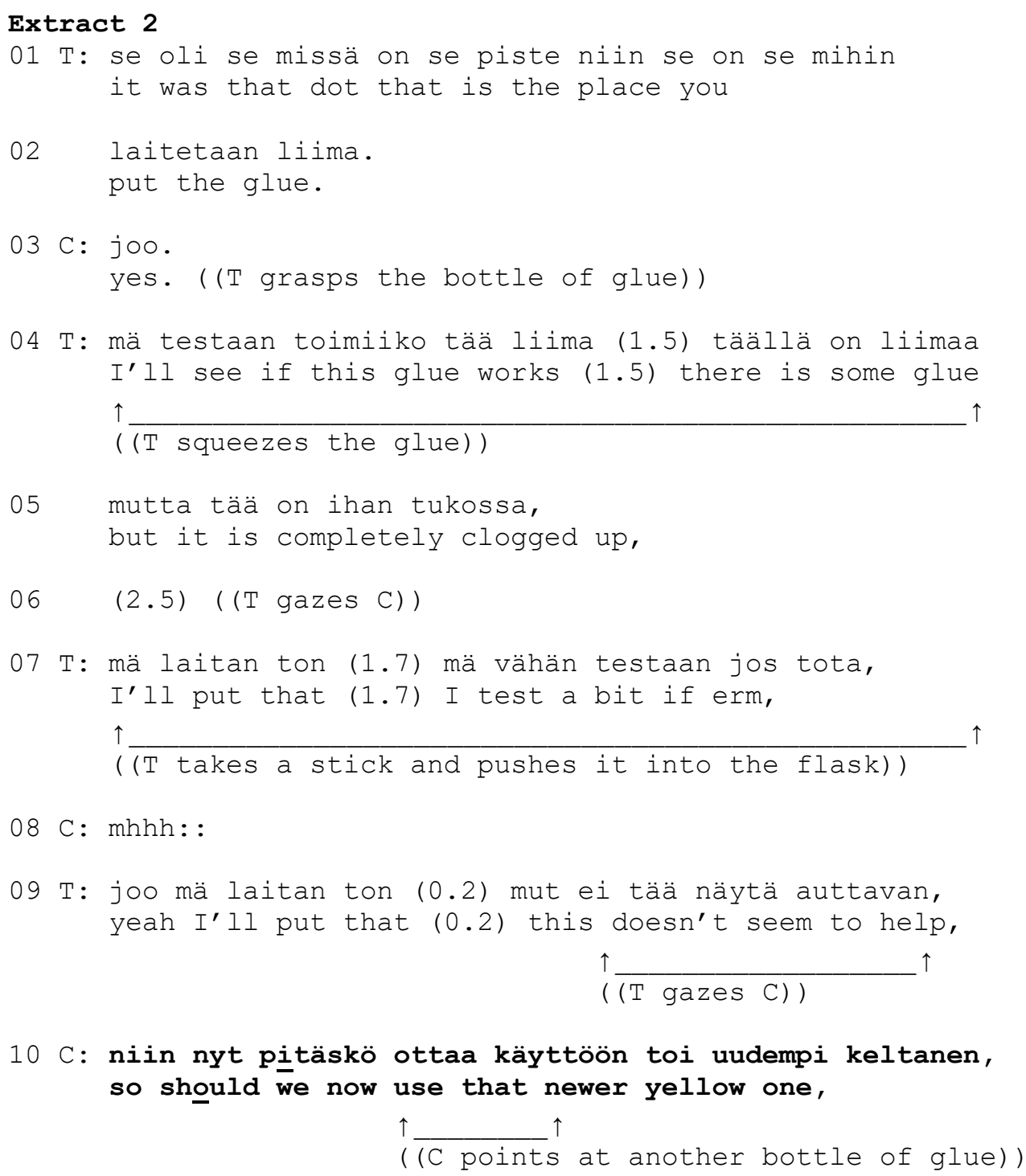


In lines 1-2, the therapist instructs the client on how to glue the magnets, but when she grasps the bottle of glue, she notices that there is a problem: the glue seems to have dried up. The therapist tries to solve the problem by squeezing the bottle (line 4) and opening it with a stick (line 7). The therapist also uses meta-talk to describe what she is doing (lines $4-5,7$ and 9), although her actions are clearly visible to the client, who is sitting facing the therapist. Moreover, in line 9, the therapist states that her actions seem to have been unsuccessful. She also gazes at the client, offering her a slot to interfere and propose a more successful solution that would enable the progress of the activity. In line 10, the client makes such an inference and proposes that they use the other bottle of glue on the table.

Thus, while the therapist manipulates the object that can be used to solve the problem, she does not perform the whole action and overcome the problem herself. Rather, she describes her own activity steps and unsuccessful attempts and gazes at the client to invite her to participate.

In summary, therapists make room for the client's proposals by shaping the activity context. This is achieved by (1) making physical objects or materials publicly visible and/ or (2) describing their own actions relating to problems with the physical objects. In both cases, in our data, the therapist does not bring the desired activity to closure by herself; rather, she provides the client with hints on how to solve the problem and opportunities to decide how to continue.

\section{Therapists' Proposals Supporting the Client's Performance}

In addition to inviting clients' proposals, occupational therapists also make proposals themselves during small-scale activity decisions. These proposals suggest the order of the 
activity steps or the ways the performance should be achieved. Thus, these proposals work primarily as an aid or support for the client's performance. Extract 3 provides an example of a case in which the client is highly agitated, and the therapist's proposals guide her to focus on the activity at hand.

In Extract 3, the therapist and client are cooking. Before the extract occurs, they have agreed to make vegetable soup and read through the recipe. At the beginning of the extract, as they are taking out the ingredients, the client suddenly begins to talk about and show the items that she has bought from the grocery store. The client talks very fast, using unclear references, and it is difficult to follow the relationship between the things she is discussing.

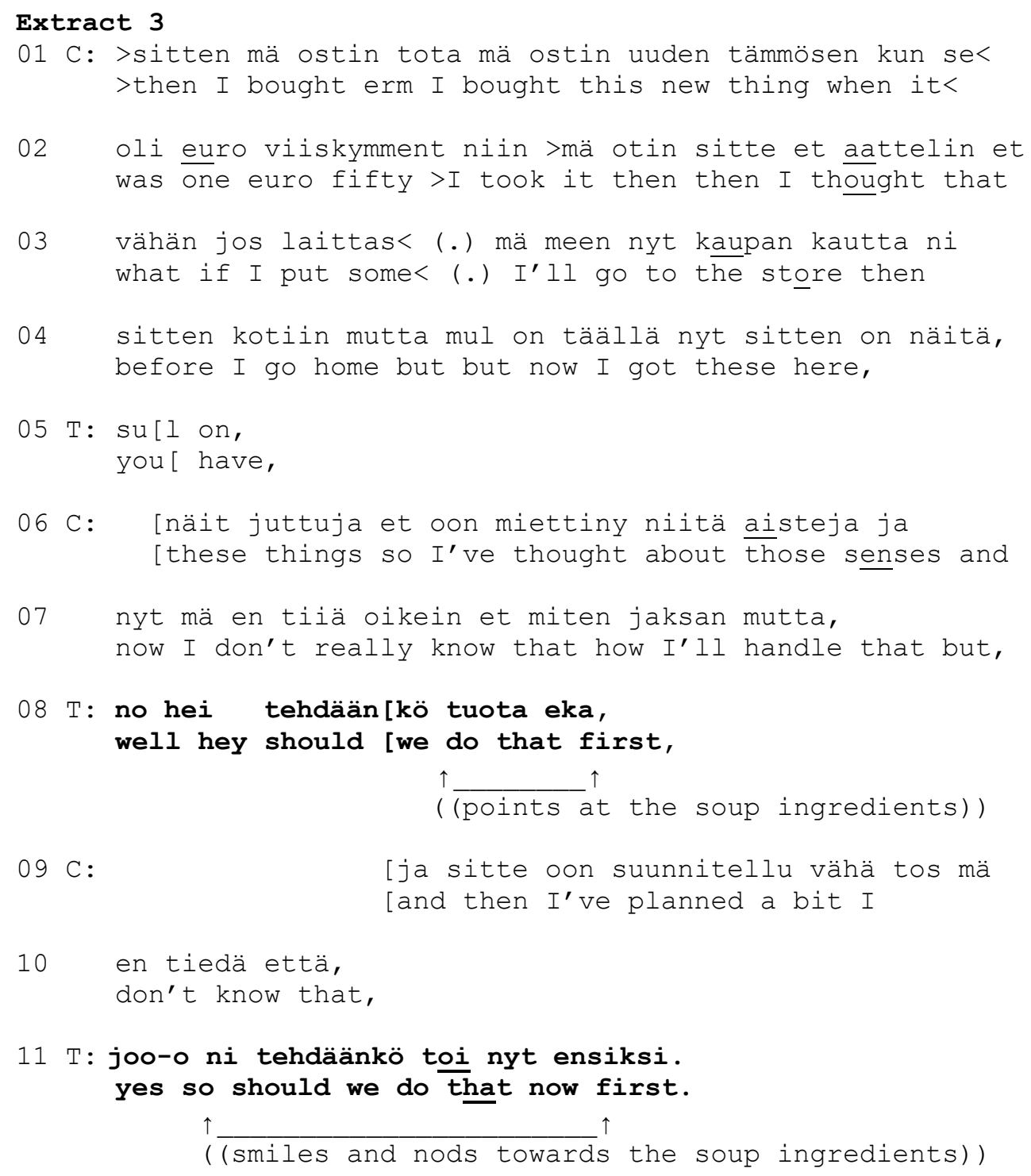




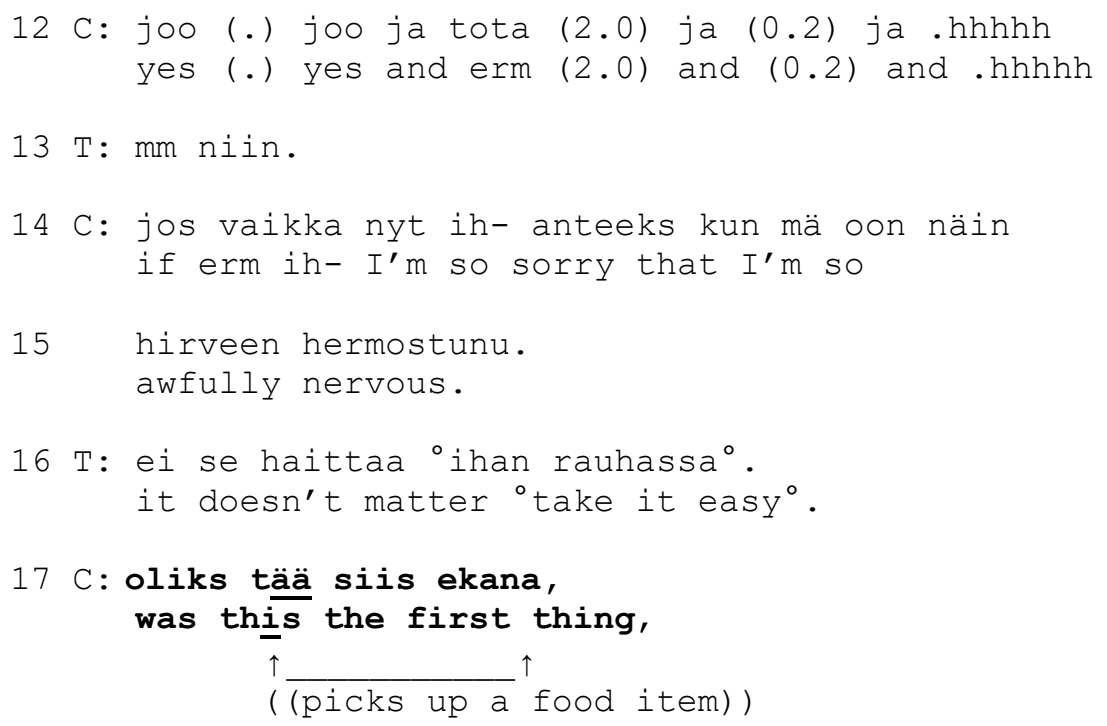

In line 1, the client, who has taken the soup ingredients from the closet, turns towards her own bag, takes out a small package of spices, and announces that she bought it because it cost only $€ 1.50$. However, it is unclear if the client is proposing that the spice be added to the soup when she asks, "what if I put some?" (line 3). It is also unclear how going to the store after the therapy meeting (lines 3-4) is related to the story or the activity at hand. The client also uses an unclear reference when talking about "these things" (lines 4 and 6) without explaining what they are. In line 5, the therapist initiates a clarifying turn ("you have"), but the client continues her account, overlapping with the therapist's talk. The client now begins to talk about "senses" (line 6), which are seemingly unrelated to anything that has been discussed during the session. She refers to these senses as something she is unable to handle (line 7).

At this point, the therapist takes a turn and makes a proposal. She points at the soup ingredients and suggests the activity order - what they could do "first" (line 8). The client, however, continues once more with her account, again overlapping with the therapist's talk (lines 9-10). In line 11, the therapist proposes for a second time that they first make the soup. She smiles and nods towards the soup ingredients, giving the impression that she is gently 
guiding the client toward the activity at hand. The client hesitates, inhales deeply (line 12) and apologizes for being in such a nervous state (lines 14-15). After that, the client refocuses on the food items on the table and continues the activity. In line 17, the client presents herself as an active agent who understands the therapist's proposal and accepts it.

Thus, in cases in which the client is agitated or faces other challenges in focusing on the activity at hand, therapist proposals that suggest the order of the activity steps can assist the client's performance. These proposals seem to invite clients' participation and provide them with an opportunity to be active agents who are in control of their own activity performance. These proposals also created an interactional environment in which topics other than issues relating to the activity performance could be raised and discussed. This is demonstrated in Extract 4.

Extract 4 is from a later part of the same session from which Extract 1 was drawn. Here, the therapist has printed the text they are planning to place on the card, which they have slightly modified (see Chapter 8 in this volume on writing in decision-making). In line 1 , the therapist and client are looking at the printed text, and the therapist asks if the client is satisfied with it.

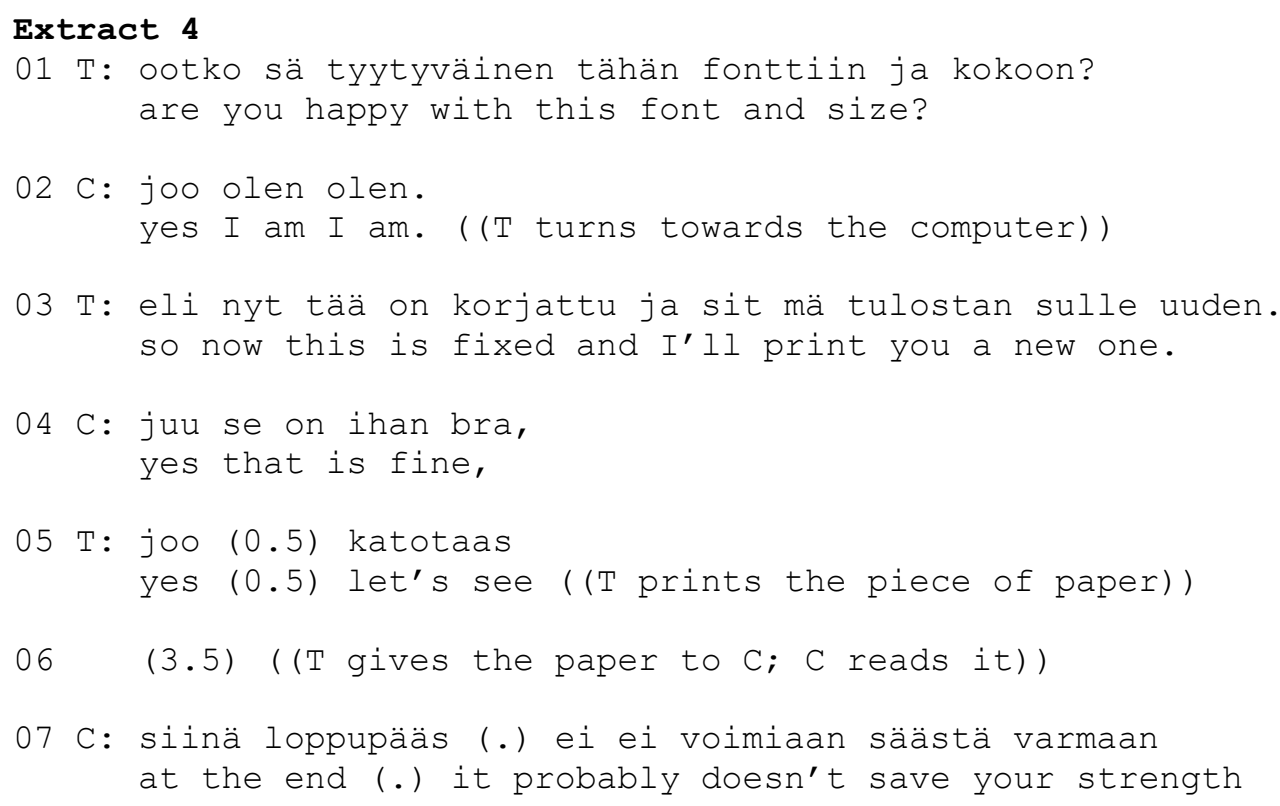




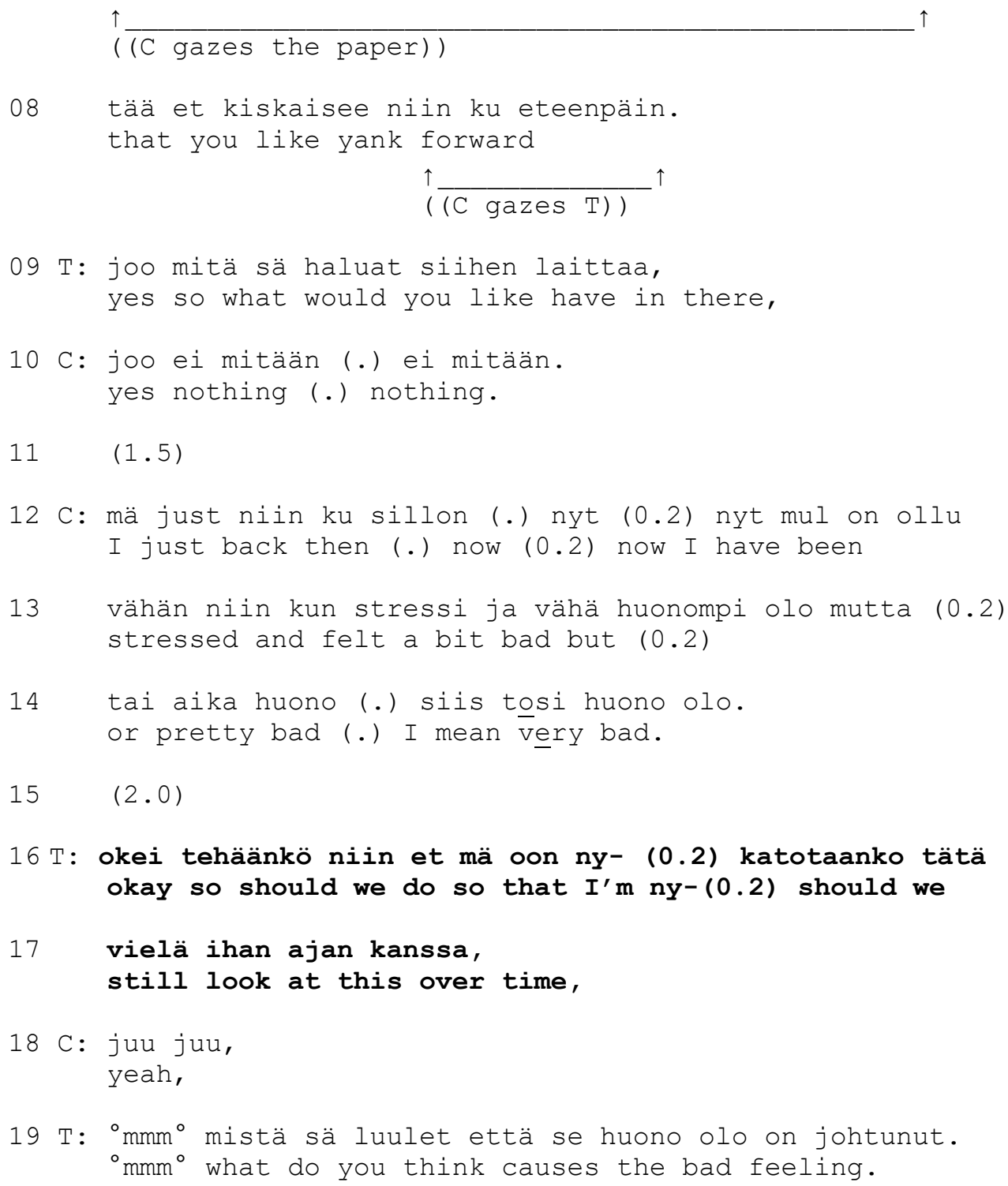

In line 1 , the therapist asks if the client is happy with the text, and she also announces that the text has been corrected according to the client's wishes, thereby seemingly treating the text as ready. First in line 2 and then in line 4, the client confirms that she is happy with the text. In line 5, the therapist prints out the piece of paper and gives it to the client. When reading it, the client highlights some parts of the text ("doesn't save your strength", line 7 and "yank forward", line 8) without explaining if or how she wants to correct them. At the end of line 8 , the client also turns her gaze from the piece of paper to the therapist, seemingly waiting for her to respond. The therapist orients to the client's turns as a request to change the text and asks how the client would like to modify it (line 9). In line 10, the client nonetheless 
withdraws, saying that she wants "nothing." After a silence in line 11, the client continues by starting to describe how she has felt stressed and bad. She also upgrades her description from feeling "a bit bad" (line 13) to "pretty bad" and eventually to "very bad" (line 14). At this point, the therapist proposes that they look at the text "over time" (lines 16-17), thus reducing the pace of the activity performance. The client agrees (line 18), and the therapist then asks more about the reasons for the client's feelings of distress. Thus, while still performing the activity at hand, the therapist focuses the talk on the client's feelings.

In addition to helping the client focus on the activity at hand (Extract 3), the therapist can also use proposals to create an interactional environment in which other topics, such as the client's difficult emotional experiences, can be discussed (Extract 4). Thus, therapists' proposals seem to work as an aid for supporting the client's performance and management of the activity at hand.

\section{Discussion}

The analysis revealed that occupational therapists perform two types of interactional work when inviting the client's participation in small-scale activity decisions. First, they make room for the client's proposals by shaping the activity context. In my data, they invited the client's proposals by noticing materials and making them publicly visible (Extract 1 ) and by describing their own actions related to problems with the physical objects (Extract 2). Therefore, the therapists exploited physical, mutable objects as a part of the decision-making sequence (see Fazulo \& Monzoni, 2009). Here, the therapists did not complete the activity themselves; rather, they used objects to hint at how to solve the problem and decide how to continue. In this way, they were able to enhance client participation and the progression of the activity at hand. 
Second, in addition to inviting the client's proposals, the therapists also made proposals themselves. The proposals were used to suggest the order of activity steps or the ways the performance should be achieved (Extract 3). By closely monitoring the client's occupational performance and proposing the order of activity steps, the therapist could facilitate the client's engagement in the activity and help her focus on the activity at hand (see Taylor, 2008). In sum, the analysis demonstrated that clients were provided decision-making power over the substantial matters of the activity, whereas therapists used decision-making power to assist the client's occupational performance and manage the progression of the activity at hand.

The therapists also used proposals to create an interaction environment in which talk could be centered on the client's current feelings (Extract 4). In such cases, the proposals subtly guided the focus of the talk away from the activity. Thus, although they continued to perform the activity, the proposal reduced the pace of the performance, thereby providing the therapist with an opportunity to concentrate on the client's current emotional experience.

Thus, it seems that even though the therapist invited the client to make activity decisions, the goal was not an end-product and a change in the environment caused by the action (Parsons, 1937); rather, the action was seen as a goal in itself (e.g., Arendt, 1958). Extracts 3 and 4 also showed how the therapist's proposals could serve as an arena in which the emotional reactions that stem from and influence the client's occupational engagement can be managed. The therapists' proposals are a momentary locus of interaction where the client's emotions and its implications for occupational participation can be addressed (see Taylor, 2008).

In the present dataset, imperfections and problems during the activities provided possible decision-making moments, with a slowing of the pace of the activity creating the opportunity to decide how to proceed. In Extract 1, the client had difficulty solving a problem 
related to the size of the piece of paper. The therapist did not rush to solve the problem but offered the client a clue that enabled the client to suggest a way forward. In Extract 2, the therapist made her own difficulty visible and thus offered the client an opportunity to propose a solution. The therapist positioned herself as unknowledgeable, thereby allowing the client to share responsibility and increasing the client's power to decide how to proceed (see Epstein et al., 2005; Weiste, Voutilainen, \& Peräkylä, 2016). In this way, clients' active involvement in the therapeutic processes is supported, and they are encouraged to adopt the role of experts in the activity they are performing (Sumsion, 2006; Weiste, 2018). The therapists' practices also revealed a rehabilitative approach, whereby the therapists avoided completing activities in which difficulties were encountered and instead helped clients to find a way to act and resolve the situation themselves (see WFOT, 2012).

The findings highlight the ideal of a reciprocal relationship between the therapist and client (see Harra, 2014). Shared activity allows both parties to adopt the role of equal actors in addition to those of a client and a professional (Harra, 2014). Equality can also be constructed through interaction, by explicitly expressing views about future activities as proposals. A proposal compared to a request or announcement situates both parties in the interaction as equal to decide on future action (Stevanovic, 2012).

But then again, therapists explicitly compensate for their clients' inabilities by supporting client participation and creating decision-making opportunities. The decisions are small enough to be considered the "small agency" described by Honkasalo (2013), when agency is constructed as a starting point for clients to become still and even tolerate their present situation. When a client is too ill or disabled to participate fully in the therapeutic process, the therapist may have to take responsibility for decision making, remaining aware of the risk of imposing their own goals and values (Creek, 2014, p. 33). One of the goals of occupational therapy will then be to work towards increasing client understanding, autonomy 
and choice (Creek, 2014). Thus, for clients with severe and chronic mental health problems, even such small-scale decisions can be important from the perspective of respecting their self-determination and allowing them to express their own will (e.g., Sumsion, 2006). This is also thought to teach clients the skills needed to make decisions that are considerably more significant, such as treatment decisions, which are related to the clients' own care (e.g., Taylor, 2008; see also Chapter 2 in this volume).

As my data demonstrated, joint desired action and therapists' proposals in particular are also used to achieve therapeutic goals, such as structuring the client's occupational performance. Here, therapists use their decision-making power to assist the client's performance but provide the client with opportunities to make the decision concerning the content of the activity. Thus, although the therapeutic relationship can never be completely equal, these practices enable the client to be considered an active subject rather than the object of the professional's performance.

\section{References}

Arendt, H. (1958). The human condition. Chicago: University of Chicago Press

Beitinger, R., Kissling, W., \& Hamann, J. (2014). Trends and perspectives of shared decision-making in schizophrenia and related disorders. Current Opinion in Psychiatry, 27(3), 222-229.

Bergmann, J. (1990). On the local sensitivity of conversation. In I. Markovà \& K. Foppa (Eds.), The Dynamics of Dialogue (pp. 201-226). Hemel Hempstead: Harvester Wheatsheaf.

Charles, C., Gafnv, A., \& Whelan, T. (1997). Shared decision-making in the medical encounter: what does it mean? (or it takes at least two to tango). Social Science and Medicine, 44(5), 681-692. 
Creek, J. (2014). The knowledge base of occupational therapy. In W. Bryant, J. Fieldhouse, \& K. Bannigan (Eds.), Creek's occupational therapy and mental health (pp. 27-47). Edinburgh: Elsevier.

Epstein, R.M., Franks, P., Fiscella, K., Cleveland, G.S., Meldrum, S.C., Kravitz, R.L., \& Duberstein, P.R. (2005). Measuring patient-centred communication in patient-physician consultations: Theoretical and practical issues. Social Science and Medicine, 61(7), 15161528.

Fasulo, A., \& Monzoni, C. (2009). Assessing mutable objects: A multimodal analysis. Research on Language and Social Interaction, 42(4), 362-376.

Hakulinen, A., Vilkuna, M., Korhonen, R., Koivisto, V., Heinonen, T. R., \& Alho, I. (2004). Iso suomen kielioppi. [Extensive Finnish Grammar] Helsinki: Suomalaisen Kirjallisuuden Seura. http://scripta.kotus.fi/visk

Hammell, K.R. (2014). Belonging, occupation, and human well-being: an exploration. Canadian Journal of Occupational Therapy, 81(1), 39-50.

Harra, T. (2014). Terapeuttinen yhteistoiminta: Asiakkaan osallistumisen mahdollistaminen toimintaterapiassa [Therapeutic collaboration. Enabling client participation in occupational therapy]. Rovaniemi: Acta Universitatis Lapponiensis.

Heritage, J. (2011). Conversation analysis: Practices and methods. In D. Silverman (Ed.), Qualitative research: Theory, method and practice (pp. 208-230). London: Sage.

Hibbard, J.H., \& Greene, J. (2013). What the evidence shows about patient activation: Better health outcomes and care experiences; fewer data on costs. Health Affairs, 32(2), 207214.

Honkasalo, M. (2013). Katveessa. Pieni toimijuus kriittisenä avauksena toiminnan teoriaan [In shades. Small agency as a critical opening to the activity theory]. Tiede \& Edistys, 1 , $42-61$. 
Kielhofner, G. (2002). A model of human occupation. Theory and application. Baltimore: Williams \& Wilkins.

Parsons, T. (1937). The structure of social action. New York: The Free Press.

Sidnell, J., \& Stivers, T. (Eds.) (2013). The handbook of conversation analysis. Chichester: Wiley-Blackwell.

Stevanovic, M. (2012). Establishing joint decisions in a dyad. Discourse Studies, 14(6), 779803.

Sumsion, T. (2006). Overview of client-centred practice. In T. Sumsion (Ed.), Client-centred practice in occupational therapy. A guide to implementation (pp. 1-19). Philadelphia: Elsevier.

Taylor, R. (2008). The intentional relationship. Occupational therapy and use of self. Philadelphia: F.A. Davis Company.

WFOT (2012). Definition of occupational therapy. Retrieved 22.5.2019 from www.wfot.org. Weiste, E., Voutilainen, L., \& Peräkylä, A. (2016). Epistemic asymmetries in psychotherapy interaction: Therapists' practices for displaying access to clients' inner experiences. Sociology of Health \& Illness, 38(4), 645-661.

Weiste, E. (2018). Relational interaction in occupational therapy: Conversation analysis of positive feedback. Scandinavian Journal of Occupational Therapy, 25(1), 44-51.

WHO (2010). User empowerment in mental health - a statement by the WHO Regional Office for Europe. Retrieved 11.1.2019 from http://www.euro.who.int/_data/assets/pdf_file/0020/113834/E93430.pdf 